\title{
Lipase-Catalyzed Interesterification for the Synthesis of Medium-Long-Medium (MLM) Structured Lipids - A Review
}

\author{
Qabul Dinanta Utama'®, \\ Azis Boing Sitanggang ${ }^{1,2} \odot$, \\ Dede Robiatul Adawiyah, ${ }^{1,2}$ \\ and Purwiyatno Hariyadi, ${ }^{1,2 *}$ \\ 'Department of Food Science and \\ Technology, Faculty of Agricultural \\ Engineering and Technology, IPB \\ University (Bogor Agricultural \\ University), Darmaga, 16680 Bogor, \\ Indonesia \\ ${ }^{2}$ Southeast Asian Food and Agricultural \\ Science and Technology (SEAFAST) \\ Center, IPB University (Bogor \\ Agricultural University), Darmaga, \\ 16680 Bogor, Indonesia
}

Received: 6 September 2018 Accepted: 7 August 2019

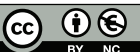

*Corresponding author:

Phone: +622518629903

Fax: +622518629903

E-mail: phariyadi@apps.ipb.ac.id

\section{SUMMARY}

Medium-long-medium (MLM) structured lipids typically contain medium-chain fatty acids (C6-C12) at sn-1,3 and long-chain fatty acids (C14-C24) at sn-2 positions. They have reduced calories and are suitable for the control of obesity, lipid malabsorption and other metabolic disorders. This review focuses on the synthesis of MLM lipids by the enzymatic interesterification. It gives detailed description of biocatalysts, substrates, reactors and synthesis methods, and discusses the use of MLM lipids in food products. The information provided in this review can be considered as the current state-of-the art for developing a future strategy for the synthesis of MLM structured lipids.

Key words: glycerides, interesterification, lipase, medium-long-medium structured lipids

\section{INTRODUCTION}

The carbon chain length, number of double bonds, and the position of fatty acids in triacylglycerol (TAG) molecules are very important factors affecting physicochemical, functional and nutritional properties of lipids (1,2). Long-chain fatty acids (LCFA: C14-C24), especially monounsaturated fatty acids (MUFA) and polyunsaturated fatty acids (PUFA), have been shown to have health benefits for human body (3). PUFA are widely known as essential fatty acids (4). The presence of PUFA in human body plays important roles for the prevention of various diseases and disorders, such as cardiovascular disease, inflammation, allergy, cancer, immune response, diabetes, hypertension and renal disorders (3). Furthermore, medium-chain fatty acids (MCFA: C6-C12) have been identified as quick energy sources as they are easily transported to the liver for the production of ketones (5-7). Vandenberghe et al. (8) reported that both caprylic (C8:0) and capric acid (C10:0) are effective in increasing plasma ketones, and may potentially provide constant energy for the body. In addition, it has been reported that MCFA also have a weak tendency to accumulate in adipose tissue (6,9-11).

The position of MCFA and LCFA in a TAG affects the digestion and subsequent absorption of the fatty acids. An MCFA that is located at $s n-1,3$ position is easily hydrolyzed by the lipase, shown by a higher possibility to be absorbed than any LCFA $(5,12,13)$. On the other hand, LCFAs located at $s n-1,3$ position are more likely to react with calcium to form soap (1). Stuctured lipids containing combinations of LCFA at $s n-2$ and MCFAs at $s n-1,3$ position, so-called medium-long-medium (MLM) TAG, will provide lipids with high coeficient absorption $(14,15)$. It has been reported that MLM structured lipids have a low caloric value, and can be used to control obesity, fat malabsorption, and other metabolic disorders $(2,16-18)$. However, an MLM lipid is rarely found in nature in a high concentration, therefore, there is a need for developing its preparation.

MLM structured lipids as reported in the literature are mostly synthesized by enzymatic interesterification, as compared to chemical interesterification. The enzymatic interesterification has some advantages due to its specificity and mild reaction conditions, hence producing fewer byproducts (19-22). Hereby, this review will focus on the underlining factors for the enzymatic interesterification for production of MLM TAGs, including 
the biocatalysts, substrates, reactor configurations, synthesis methods, and other reaction conditions. Additionally, this review also presents the potential applications of MLM structured lipids, particularly in food industry.

\section{ENZYMES FOR MLM STRUCTURED LIPID SYNTHESIS: TYPES ANS SOURCES}

Lipases are enzymes belonging to the hydrolase group, capable of catalyzing both hydrolysis and esterification reactions (23-25). A lower moisture content of reaction system provides a greater possibility for lipases to catalyze esterification reaction than that of hydrolysis reaction. However, the presence of small quantities of moisture is still needed for the lipases to maintain their catalytic activities (26). Generally, the active site of a lipase is responsible for its catalytic activity and it consists of a triad of serine, histidine and aspartate or glutamate (His-Ser-Asp/Glu). This catalytic triad is buried under the 'lid' of the surface circle that undergoes conformational changes due to interfacial activation. These conformational changes result in the availability of open channels for facilitating active sites that are correctly oriented for the substrates (27).

The mechanism of lipase-catalyzed esterification consists of three steps (24). In the first step, the active sites of serine are activated by deprotonation using histidine and aspartate. Further, the serine active sites react with the carbonyl group of the substrates forming an acyl-enzyme intermediate, stablized by oxyanion hole. Finally, such deacylation is performed where a nucleophile (e.g. $\mathrm{H}_{2} \mathrm{O}$ or monoglyceride) attacks acyl-enzyme intermediate to release a product and regenerate unoccupied catalytic sites. Electronegativity of the molecules populating the interface controls this process (24).

Animals, plants and microbes (fungi, yeast and bacteria) have been identified as sources of lipases (28). Generally, microbial lipases have higher stability than plant and animal lipases (29). There are numerous studies of the characteristics of microbial lipases (i.e. mostly extracellular bacterial and fungal lipases), and their versatility makes them very attractive for industrial applications (30).

In general, based on their mode of action, lipases can be classified as non-specific and specific lipases. A non-specific lipase acts randomly and produces a similar mixture of products to that of a chemical interesterification (16). On the other hand, a specific lipase acts uniquely towards producing specific type of product, and can be subclassified based on positional, substrate or stereo specificity $(31,32)$. An sn-1,3-specific lipase, a lipase that has preference to react solely with acyl groups at $s n-1,3$ positions (Fig. 1), is widely used as a catalyst for MLM lipase synthesis. Lipases from Thermomyces lanuginosa and Rhizomucor miehei have been identified to have sn-1,3 positional specificity (19). Additionally, several studies have reported that lipases from Geotrichum candidum (33) and Candida antartica $(34,35)$ show a moderate preference for $s n-2$ position. A stereospecific lipase hydrolyses fatty acids at $s n-1$ and $s n-3$ positions at different rates. Therefore, besides the influence of its source, the catalytic activity largely depends on the substrate concentration $(31,32)$. On the other hand, a substrate-specific lipase shows specificity to certain fatty acids (i.e. saturated or unsaturated fatty acids, long, medium or short chain fatty acids) and the type of acylglycerols (mono-, di-, or tri-acylglycerol). Rodrigues and Fernandez-Lafuente (36) reported that Rhizomucor miehei lipase showed a high activity in acidolysis, while Thermomyces lanuginosa lipase in alcoholysis or transesterification reaction. The specificity of either positional, substrate or stereospecific lipase is also affected by the solvent polarity or partition coefficient $(\log P)$ (hydrophobic/hydrophilic coefficient), water activity $\left(a_{\mathrm{w}}\right)$, immobilization carrier, and reaction conditions $(37,38)$.

The stability of enzymes is an important aspect for industrial applications due to their high cost. Lipase stability is

a)

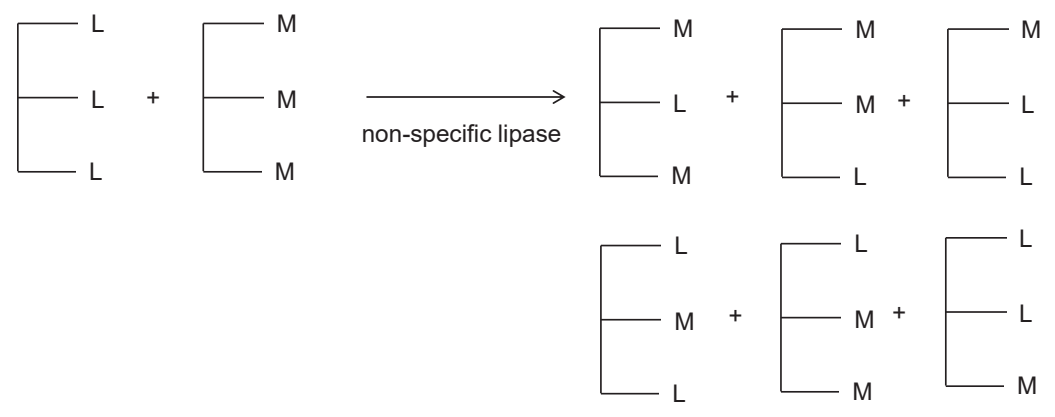

b)

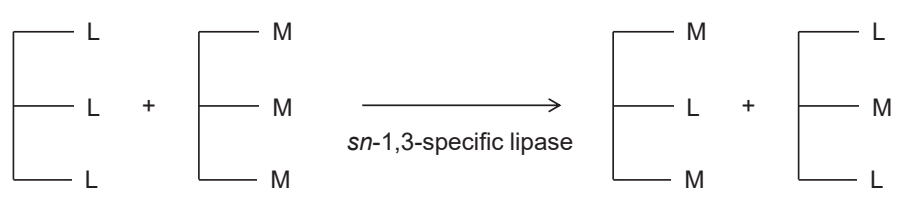

Fig. 1. Synthesis of medium-long-medium (MLM) structured lipids by: a) non-specific lipase, and b) sn-1,3-specific lipase 
affected by the reaction conditions, including moisture content $\left(a_{\mathrm{w}}\right), \mathrm{pH}$, temperature, substrate composition, product concentration and lipase concentration $(25,32)$. The enzyme immobilization and enzyme modifications through protein/ genetic engineering are an interesting area to increase enzyme stability. Immobilized lipases show higher stability at elevated temperatures in microaqueous systems than in free form (26). Several commercial immobilized lipases, including Lipozyme RM IM (from Rhizomucor miehei) (39-41), Lipozyme TL IM (from Thermomyces lanuginosa) $(38,42,43)$, and Novozyme 435 (44), have been widely used for investigations. Lipozyme TL IM has a lower price than other commercial lipases (22). Furthermore, its use in batch reaction effectively changes the TAG composition of palm olein, yet shows high acyl migration (45). Cao et al. (46) also confirmed that this lipase, as compared to that from Rhizopus oryzae, has a tendency to cause acyl migration. Lipozyme TL IM has a higher total transesterification activity than Lipozyme RM IM (39). Moreover, sn-1,3 positional specificity of Lipozyme RM IM is slightly higher than that of Lipozyme TL IM (42). Nunes et al. (47) reported that the highest incorporation of caprylic acid into olive oil was obtained by using Novozyme 435 and Lipozyme RM IM as catalysts. Khodadadi et al. (43) also reported that Lipozyme TL IM and Novozyme 435 were more effective in transesterification reaction between flaxseed oil and tricaprylin than Lipozyme RM IM and Amano DF. Table 1 (44, 48-53) summarizes the utilization of immobilized lipase for MLM lipase synthesis.

Genetic engineering techniques (i.e. rational design, directed evolution, etc.) have been developed to modify native lipases from different microorganisms. These have improved lipase activity, stability, regioselectivity and enantioselectivity (25). Additionally, genetically engineered lipases are also expected to reduce the cost of lipases and facilitate economically affordable enzymatic reactions (2). Other than lipases, genetic engineering techniques have also been conducted in lipid-containing plants to produce the desired composition of lipids or oils. Sunflower oil normally contains only 16 to $20 \%$ of oleic acid (2), but through mutagenesis, sunflower cultivars can contain $90 \%$ of oleic acid and less than $7 \%$ saturated fatty acids.

\section{SOURCES AND TYPES OF SUBSTRATES FOR MLM LIPID SYNTHESIS}

Vegetable oil, fish oil, animal fats, single TAG molecules, or free fatty acids can be used as sources of LCFAs and MCFAs for MLM structured lipid synthesis. Oil that contains high concentrations of MUFAs or PUFAs at $s n-2$ position can be considered as LCFA source, and as a potential substrate. A higher concentration of oleic acid (C18:1) at sn-2 position can be found in several types of vegetable oil, including palm olein, olive oil, and canola oil (54,55). Linoleic acid (C18:2) can be found in soybean oil, cottonseed oil, sunflower oil and safflower oil, while fish oil products are widely known as sources of eicosapentaenoic (EPA, C20:5) and docosahexaenoic acid (DHA, C22:6). Moreover, palm kernel oil and coconut oil are reported as sources of MCFAs, containing higher amounts of lauric acid predominantly at $s n-1,3$ positions (40). Other potential substrates in MLM synthesis can be seen in Table 2 (39,43,56-59).

Generally, vegetable oil or fish oil are sources of LCFAs for MLM structured lipid synthesis (Table 2) while vegetable oil, single TAG molecule (tricaprylin, tricaprin, etc.) and free fatty acids are MCFA sources. Several combinations of substrates for MLM lipid synthesis have been reported such as tricaprylin and trilinolenin (59), triolein and caprylic acid (60), olive oil and caprylic acid $(61,62)$, modified pine nut oil and capric acid (63), canola oil and caprylic acid $(64,65)$, soybean oil and caprylic acid (7,66-68), and corn oil and caprylic acid (69).

Besides the substrate availability and price, its purity is another factor that requires consideration. It has been reported that minor compounds found together with the lipids, such as hydroperoxides, phospholipids, emulsifiers, chlorophyll, carotenoids, lipid polymers, heavy metals, and even some antioxidants, have remarkable effect on the stability of lipases (35). Therefore, it is worth noting that the use of a high-quality initial substrate for MLM structured lipid synthesis can minimize enzyme stability loss.

The specificity of enzymes during MLM lipid synthesis may also be affected by the medium of reaction system. Generally, for lipase-catalyzed interesterification, MLM structured lipid synthesis can be performed in either solvent system (i.e.

Table 1. Immobilized lipase for the synthesis of medium-long-medium (MLM) structured lipid

\begin{tabular}{|c|c|c|c|c|}
\hline Enzyme & Source & Specific/non-specific & Immobilization material & Reference \\
\hline Lipase Lip2 & Yarrowia lipolityca & $s n-1,3$ specific & Accrurel MP 1000 & (44) \\
\hline Lipozyme TL IM & Thermomyces lanuginosa & $s n-1,3$ specific & Silica gel & (48) \\
\hline Lipozyme RM IM & Rhizomucor miehei & $s n-1,3$ specific & Resin & (49) \\
\hline Novozyme 435 & Candida antartica & $s n-1,3$ specific & Acrylic resin & $(49,50)$ \\
\hline Lipozyme 435 & $\begin{array}{l}\text { Recombinant lipase from Candida } \\
\text { antartica, expressed on Aspergillus niger }\end{array}$ & $s n-1,3$ specific & $\begin{array}{l}\text { Macroporous hydrophobic } \\
\text { resin }\end{array}$ & (49) \\
\hline Lipase D and DF & Rhizopus oryzae & $s n-1,3$ specific & Accrurel MP 1000 & (51) \\
\hline Lipase QLM & Alcaligenes sp. & $s n-1,3$ specific & Accrurel MP 1000 & (51) \\
\hline Palatase $20000 \mathrm{~L}$ & Mucor miehei & sn-1,3 specific & Accrurel MP 1000 & (52) \\
\hline Lipase Rd & Rhizopus delemar & $s n-1,3$ specific & Accrurel MP 1000 & (52) \\
\hline Carica papaya lipase (CPL) & Carica papaya & $s n-1,3$ specific & Papaya latex & (53) \\
\hline Heterologous lipase & Rhizopus oryzae (rROL) & $s n-1,3$ specific & Amberlite $^{\text {TM }}$ IRA 96 & (53) \\
\hline
\end{tabular}


Table 2. Potential substrates for medium-long-medium (MLM) structured lipid synthesis

\begin{tabular}{|c|c|c|c|}
\hline Fatty acid & Source & $w($ acid $) / \%$ & Reference \\
\hline \multirow[t]{7}{*}{ Oleic acid } & Palm olein & $39.8-46.0$ & (56) \\
\hline & Canola oil & 64.1 & $(57)$ \\
\hline & Peanut oil & 46.5 & $(57)$ \\
\hline & Olive oil & $55-83$ & $(57)$ \\
\hline & Rice bran oil & $38-48$ & (56) \\
\hline & Sesame seed oil & $36.9-47.9$ & (56) \\
\hline & Avocado oil & 65.42 & (39) \\
\hline \multirow[t]{4}{*}{ Linoleic acid } & Soybean oil & $48-59$ & (56) \\
\hline & Cottonseed oil & $46.7-58.2$ & (56) \\
\hline & Sunflower oil & $48.3-74$ & (56) \\
\hline & Safflower seed oil & $67.8-83.2$ & (56) \\
\hline Linolenic acid & Flaxseed oil & 50.28 & (43) \\
\hline \multirow[t]{2}{*}{ EPA } & Krill oil & $14.3-28.0$ & $(58)$ \\
\hline & Menhaden oil & $12.5-19.0$ & $(58)$ \\
\hline \multirow[t]{4}{*}{$\mathrm{DHA}$} & Tuna oil & $21-42.5$ & $(58)$ \\
\hline & Anchovy oil & $4.0-26.5$ & $(58)$ \\
\hline & Salmon oil & $6.0-14.0$ & $(58)$ \\
\hline & Cod liver oil & $6.0-18.0$ & $(58)$ \\
\hline \multirow[t]{3}{*}{ Lauric acid } & Palm kernel oil & $45-55$ & $(56)$ \\
\hline & Coconut oil & $45.1-53.2$ & $(56)$ \\
\hline & Babassu oil & $40.5-55$ & (56) \\
\hline
\end{tabular}

organic solvents) or solvent-free system. Although organic solvents are still permitted for ingredient preparation in food production, solvent-free system is more preferred in food industries to ease the separation processes, enhance the product quality and for environmental reasons $(26,70)$. Nunes et al. (17) reported that a better incorporation of C8:0 and C10:0 into TAG was obtained in a solvent-free system than in the solvent system. However, the presence of organic solvent allows the reaction at higher temperatures (26). Higher temperatures reduce substrate viscosity, which entails reduced mass transfer and a higher reaction rate $(71,72)$. On the other hand, higher temperatures also have a negative impact on enzyme inactivation. High temperature causes only partial unfolding of the enzyme structure, especially of the primary structure due to the damage of certain amino acids (26).

The use and selection of suitable organic solvent for MLM structured lipid synthesis must take into consideration the substrate and product solubility, hydrophobic behaviour of the solvent, reactivity, density, viscosity, surface tension, environmental effects, and cost (26). There is a report that organic solvents with $\log P>3$ are the best solvents for the acidolysis of lard with capric acid (73). In another report, ionic liquid is used as alternative solvent in lipase-catalyzed reaction. The use of ionic liquid shows more technological advantages than organic solvents, such as selectivity enhancement, enzyme stability improvement, higher conversion rates, and better recyclability and recovery systems (74). However, there is still limited research using the ionic liquid in structured lipid production.

\section{METHODS OF ENZYME-CATALYZED MLM LIPID SYNTHESIS}

The appropriate methods of MLM structured lipid synthesis will affect its purity (75). In general, enzyme-catalyzed MLM structured lipid synthesis can be obtained by direct or indirect interesterification. In direct interesterification, direct reaction between substrates and enzymes produces MLM structured lipids. Depending on the used substrate, direct interesterification includes acidolysis, transesterification and esterification. Alternatively, indirect interesterification or two-step reaction is a combination of two types of direct reactions to produce MLM structured lipids $(16,75)$.

\section{Acidolysis}

Acidolysis is a reaction between acylglycerol and free fatty acids. This reaction is mostly used for MLM structured lipid synthesis. Ifeduba and Akoh (76) used soybean oil rich in stearidonic and caprylic acids as a substrate with Rhizomucor miehei lipase as a catalyst. The result showed that structured lipids contained amount ratio of $r=17-32.5 \%$ caprylic acid and 20.6-42.3\% stearidonic acid. In another study, Caballero et al. (39) attempted to incorporate caprylic acid into avocado oil (2:1 substrate ratio) using Lipozyme TL IM and Lipozyme RM IM as catalysts. The reaction was conducted in a solvent-free system at $10-50{ }^{\circ} \mathrm{C}$ for $24 \mathrm{~h}$. The highest amount ratio of caprylic acid at $s n-1,3$ positions obtained using Lipozyme TL IM as a catalyst was $29.2 \%$.

Repeated reactions can be used to increase the yield of MLM structured lipid synthesis. The repeated reactions effectively enhance the incorporation of caprylic acid at $s n-1,3$ positions. Lai et al. (77) reported that $30.5 \%$ of caprylic acid was incorporated into refined bleached deodorized palm olein. However, acyl migration that occurs in acidolysis can result in reduced purity of MLM structured lipid yield. Acyl migration is generally defined as the migration of the acyl group from $s n-2$ to $s n-1,3$ position (78). This phenomenon has been reported to be influenced by the temperature, types of immobilization carrier and organic solvent (79).

\section{Transesterification}

Transesterification is the reaction of exchange of two acyl groups between two ester molecules or TAGs. Depending on the substrates used in the reaction, there are three types of transesterification: (i) reaction between two types of vegetable oil, (ii) reaction between vegetable/fish oil and single TAG molecule, and (iii) reaction between two single TAG molecules. For the MLM structured lipid synthesis using the first type of reaction, Zhao et al. (80) used Cinnamomum camphora seed oil and camellia oil catalyzed by Lipozyme RM IM. The produced structured lipid had the oleic acid predominantly at $s n-2$ position (88.69\%) and MCFA at $s n-1,3$ position (68.05 $\%)$. A reaction between linseed oil and tricaprylin catalyzed by Lipozyme TL IM for MLM synthesis is an example of the second type of transesterification (81). Here, the amount ratio 
of caprylic acid-linolenic acid-caprylic acid was the highest (35.34-35.45 \%). Caprylic acid-linoleic acid-caprylic acid, and caprylic acid-oleic acid-caprylic acid were also produced at amount ratios of $4.09-4.19$ and $8.44-8.53 \%$, respectively. As an example of esterification type three, Bai et al. (59) reported the utilization of tricaprylin and trilinolenin as substrates, and either Lipozyme RM IM or Novozyme 435 as a catalyst. Caprylic acid-linolenic acid-caprylic acid and caprylic acid-linolenic acid-linolenic acid were reported to be the dominant products. It is conclusively considered that the MLM structured lipid synthesis using transesterification may produce various TAG species as compared to other methods. Therefore, purification of structured lipids is necessary to eliminate byproducts such as free fatty acids, monoacylglycerols (MAG) and diacylglycerols (DAG), and to obtain a higher MLM structured lipid yield. Purification methods of structured lipids can be short-path distillation (82), membrane technology (83), and solvent extraction $(50,84,85)$. In solvent extraction, hexane is used under alkaline condition to purify the structured lipid. Lu et al. (50) conducted a two-step purification using deacidification and silica gel absorption. After the purification, the product had reduced acid and peroxide values, and DAG content.

\section{Esterification}

Glycerol and free fatty acids are generally used as substrates in esterification reaction. This reaction produces a highly pure MLM with fewer byproducts than acidolysis. The esterification products can be at a higher risk of degradation as they do not contain any natural antioxidant from vegetable oils (16). Therefore, in the post-reaction step, an antioxidant has to be added to maintain the product stability. Arifin et al. (86) used glycerol and a mixture of stearic and capric acids as substrates and Lipozyme RM IM as a catalyst. The result showed that $58 \%$ medium and long-chain triacylglycerol (MLCT) was produced under optimum conditions (13.6-14.0 h reaction time, 7.9-8.0 \% $(\mathrm{m} / \mathrm{m})$ enzyme load, and 3:1 fatty acids/glycerol amount ratio). A similar study was also conducted using caprylic, capric and oleic acids, and glycerol (87). The use of non-specific lipase (Novozyme 435) in this reaction produced $72.19 \%$ MLCT (87). It has been reported that non-specific lipase is more suitable than specific sn-1,3 lipase for esterification during MLM structured lipid synthesis (87). This is due to acyl migration that can occur in specific $s n-1,3$ lipase-based MLM structured lipid synthesis.

\section{Two-step reaction}

Two-step reaction is mostly applied when using PUFA as substrates. The hydrolysis of PUFA by fungal lipase is more difficult than other fatty acids. However, this method has been reported to produce highly pure MLM structured lipids $(16,75)$. There are various strategies for structured lipid synthesis based on two-step reaction. The first approach is a combination of esterification and acidolysis (16). In the initial step, the esterification occurs between glycerol and PUFA producing tri-PUFA.
Then, acidolysis between tri-PUFA and MCFA yields MLM TAG. Kawashima et al. (88) produced MLM structured lipids using this method and EPA, gamma-linolenic acid (GLA), arachidonic acid (AA), DHA and caprylic acid. Esterification was catalyzed by Novozyme 435 to produce tri-GLA, tri-AA, tri-EPA and tri-DHA. Furthermore, acidolysis between caprylic acid and tri-GLA/tri-AA/ tri-EPA or tri-DHA was conducted to produce MLM structured lipids with mass fractions of $58,87,86$ and $19 \%$, respectively (88).

Meanwhile, in the second approach a combination of alcoholysis and acidolysis was used $(31,89)$. Firstly, vegetable or fish oil with high concentration of PUFA at $s n-2$ position reacted with an alcohol to produce 2-monoacylglycerol (2-MAG). Then, 2-MAG reacted with MCFA to produce MLM structured lipids. This strategy was adopted to produce caprylic acid-gamma linoleic acid-caprylic acid from borage oil (88). Muñío et al. (51) used similar method to produce caprylic acid-PUFA-caprylic acid from fish oil (cod liver and tuna oil). In alcoholysis, various sn-1,3-specific lipases were employed to produce 2-MAG. The highest concentration of 2-MAG was obtained using lipase D (Rhizopus oryzae lipase). However, Novozyme 435 showed better operational stability than lipase D. 2-MAG was separated using a solvent extraction with ethanol and hexane. Furthermore, 2-MAG reacted with caprylic acid to produce MLM TAG. The product contained $45 \%$ PUFA at sn-2 position. The incorporation of caprylic acid was $64 \%$, and about $98 \%$ of this incorporation were found at $s n-1,3$ position. A similar study was also performed using cod liver oil and caprylic acid (90) and about $38 \%$ DHA were found at $s n-2$ position and $60 \%$ caprylic acid at $s n-1,3$ position.

Morales-Medina et al. (91) conducted an alternative strategy to two-step reaction. In the first step, an esterification reaction catalyzed by Novozyme 435 was performed using glycerine and caprylic acid to produce 1,3-dicaprylin, which reacted with LCFA to produce MLM TAG. This method increased regiodistribution of fatty acids by $72 \%$ as compared to direct reactions (91).

\section{REACTOR FOR MLM STRUCTURED LIPID SYNTHESIS}

In lipid modification process, the selection of the reactor is of importance to produce the desired product in high quantities. Several factors important for the selection of reactor are: flexibility, efficiency, quality of the final product, stability and reusability of enzymes, and cost (92). In MLM lipid synthesis, there are two types of reactor systems commonly used: batch and continuous system $(93,94)$.

The batch reactor system is widely used to collect preliminary data on bench-to-pilot plant scale. Sometimes, this reactor is also used for production of TAG in small quantities, especially for characterization of newly isolated enzymes for process development of new products. This reactor requires simple equipment and operation (94). Limitations of this system are the difficulty to control heat transfer, and variations in batch-to-batch operation. On industrial scale, such repetitive actions in start and end procedure in every batch will result in the accumulation of unproductive time and increased labour cost. Substrate ratio, enzyme load, stirring rate, temperature, 
and reaction time influence the yield of MLM lipid synthesis in batch reactor (68). Wang et al. (65) reported that incorporation of caprylic acid in a batch production was influenced by substrate amount ratio. The maximum incorporation of caprylic acid was $45.31 \%$ at amount ratio of caprylic acid and canola oil 4:1. A higher amount ratio than this value was not found to increase the incorporation of caprylic acid. Additionally, the increase of caprylic acid amount ratio in the reaction system might induce enzyme inactivation (68). Wang et al. (65) also reported that loading of Lipozyme RM IM higher than 10 $\%$ decreased the incorporation of caprylic acid, which is in agreement with another study where maximum incorporation of caprylic acid in acidolysis was $10 \%$ of lipase load (95). On the other hand, a higher reaction temperature caused an increasing rate of reaction, but also showed enzyme denaturation and acyl migration (96). In general, a higher possibility of acyl migration also occurred at longer batch reaction time (97). Moreover, higher stirring rate caused destruction of immobilized enzymes, while lower stirring rate affects substrate homogeneity (71). Table $3(15,17,40,44,48,49,64,80,98-$ 101) shows relevant studies about batch production of structured lipids.

In continuous reactor system, substrate is fed continuously into the reactor. Moreover, the remaining or unreacted substrate together with the product flows continuously out of the reactor. Hereby, residence or retention time plays an important role for obtaining a higher reaction rate. In general, there is a distinction between a continuous stirred tank reactor (CSTR) and plug flow reactor or packed bed reactor (PBR). In CSTR, the samples are homogeneously mixed, and the temperature is maintained at each point inside the reactor. PBR is a reactor system where the substrate mixture passes through a reactor tube containing immobilized enzyme molecules. PBR has several advantages such as ease of operation, better product control, and high reaction rate and mass transfer (93). This reactor is commonly used for MLM structured lipid synthesis in continuous system (102-104).

Substrate flow in PBR system can be performed either downward or upward through the application of metering pump. For downward flow, the substrate enters from the top of the reactor and the product will exit from the bottom of the reactor collected in the product reservoir. This method causes faster flow rates (thus shorter residence time) due to the gravity effect besides pressure gradient produced by the work of the pump. Contrary to the downward flow, in the upward flow the substrate flows from the bottom of the reactor and the product will exit through the top of the reactor. This method is more common in industrial applications (105).

In addition to the two aforementioned flow strategies in PBR, a substrate flow can also be maintained using recycling method $(93,106)$. The recycling method is carried out by streaming the mixture of unreacted substrate and product out of the reactor and pumping it back into the reactor. Generally, similar to batch reactor, this method uses stirrers for both reactor and substrate reservoir to facilitate continuous stirring and maintaining substrate homogeneity (107). The advantage of this strategy is the increase of product yield as substrate is repetitively exposed to and catalyzed by the enzyme. Here, the product will be taken periodically from the substrate reservoir.

Paez et al. (103) reported the MLM structured lipid synthesis using caprylic acid and cod liver oil as substrates and Lipozyme IM as a catalyst. The reaction was performed in three reactor configurations: batch, PBR with recycling flow (discontinuous) flow, and PBR with continuous flow (Fig. 2). In Fig. 2, the dashed line shows the substrate flow in recycling mode (discontinuous), whereas the dotted line shows the substrate flow in continuous mode. A similar study was also conducted using tuna oil and caprylic acid to synthesize MLM TAG in a packed bed

$\mathrm{f}$

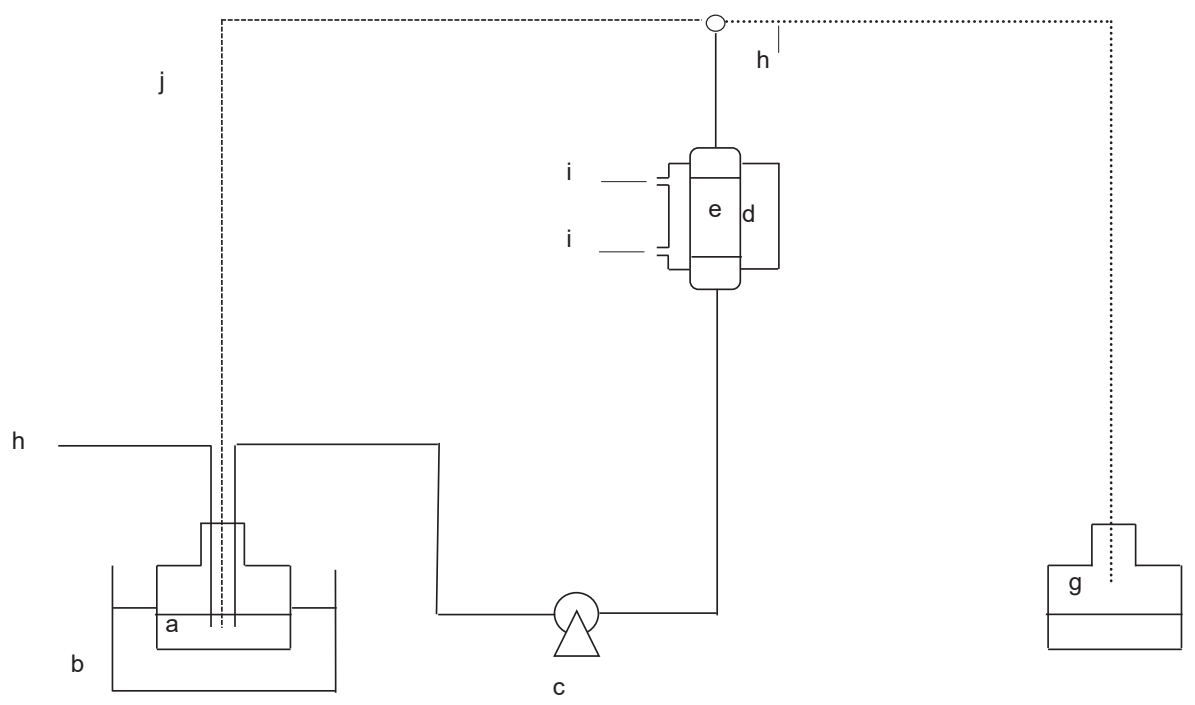

Fig. 2. Packed bed reactor with single (continuous) and recycling (discontinuous) flow: a) substrate reservoir, b) reactor temperature control, c) peristaltic pump, d) water jacket, e) packed bed reactor, f) three-way valve, g) product reservoir, h) sampling, i) cooling/heating water, and j) recirculation (103) 


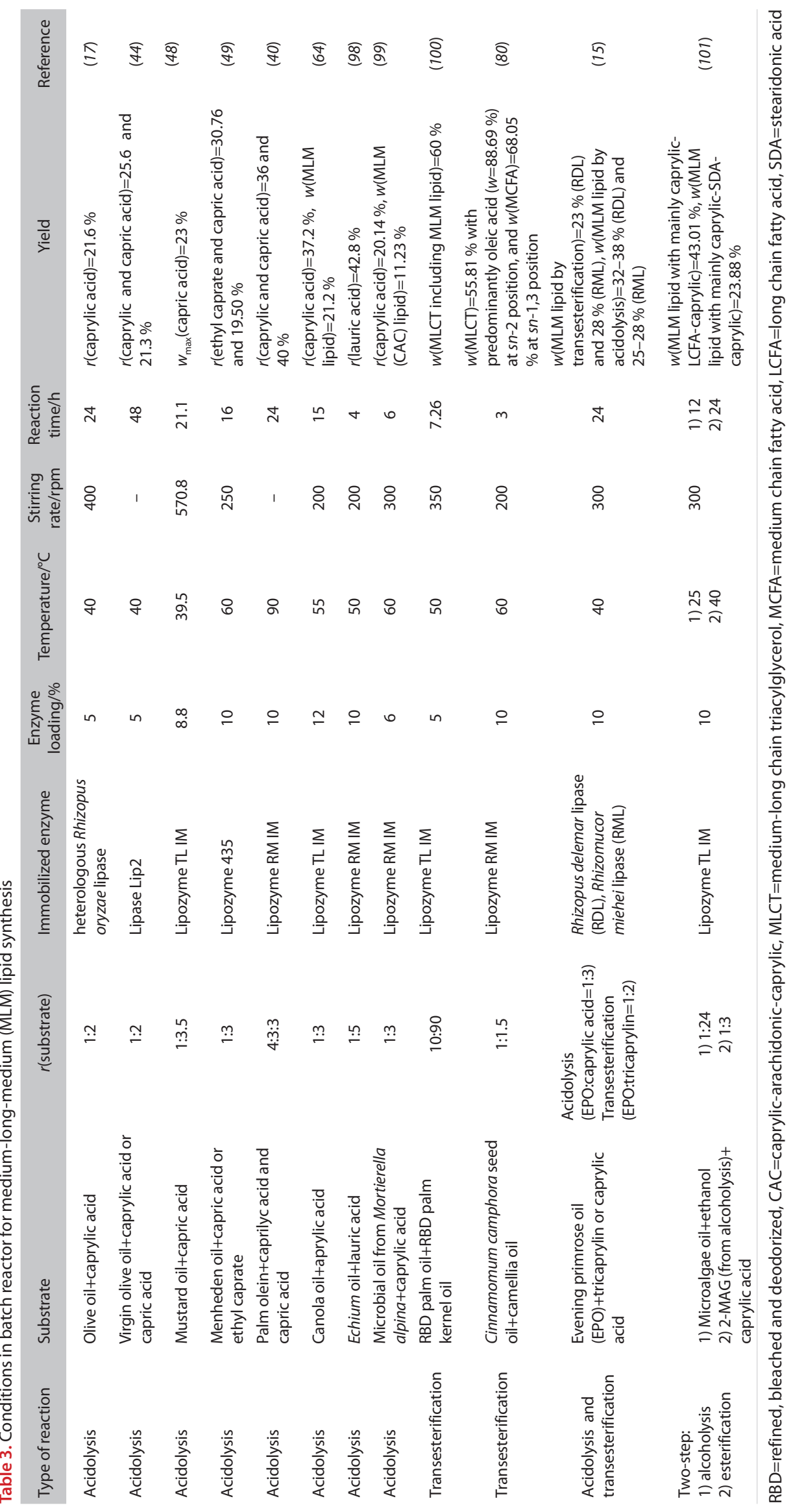


reactor (52). The result showed that incorporation of higher amount of caprylic acid into tuna oil was obtained in discontinuous flow than in continuous flow. In contrast, Gonzáles Moreno et al. (108) reported that incorporation of caprylic acid into fish oil using PBR was higher in continuous flow than in the discontinuous flow (recycling flow). In addition, a higher EPA content was achieved in continuous flow. It seems that other factors such as enzyme and substrate types, and substrate amount ratio might also play an important role in MLM lipid synthesis. Table 4 (42,52, 63, 109,110) summarizes literature about MLM structured lipid synthesis in a continuous system.

\section{APPLICATIONS OF MLM STRUCTURED LIPIDS}

The digestion of lipids in human body occurs when the lipase is present. The lipases involved in this process are lingual, gastric, pancreatic and co-pancreatic, found in the mouth, stomach, and small intestine, respectively (55). However, the major digestion and absorption of lipid derivatives are located at the small intestine, especially duodenum, in the presence of pancreatic and co-pancreatic lipase (55). Pancreatic and co-pancreatic lipases specifically hydrolyze fatty acids at $s n-1$ and sn-3 positions, respectively (55). MLM TAG are hydrolyzed by pancreatic lipase to produce 2-MAG and two free fatty acids. The rate of hydrolysis of the MLM ( $M=C 8: 0$ or C10:0, $L=C 18: 2)$ is twofold higher than that of LML lipids (long-medium-long) (111). In animal studies, Ikeda et al. (112) showed that the absorption of linoleic acid was higher than of trilinolein in MLM (capric acid-linoleic acid-capric acid) lipids. This was probably due to faster hydrolysis rate of MCFA. In addition, the absorption of LCFA is higher when they are located at the $s n-2$ position $(113,114)$. Saturated LCFA, such as palmitic and stearic acids, absorb better the total MLM lipids than LML lipids (115). In LML lipids, saturated fatty acids escape from the outer position of TAG (sn-1 and sn-3 positions) during lipolysis, and form calcium soaps that are excreted through the faeces (5). In addition, human body absorbes more easily the PUFA at the $s n-2$ position than 2-MAG. Therefore, it is important to maintain LCFA at the $s n-2$ position.

Various studies have explored the potential applications of MLM lipids in food products. Currently, there is no commercial pure MLM lipid product on the market. Small quantities of MLM lipids can be found commercially in Resetta, a commercial MLCT product manufactured by Nisshin Oillio Group Ltd. Tokyo, Japan. This product was categorized as Food for Specific Health Uses (FOSHU) in Japan in 2002, and received Generally Recognized as Safe (GRAS) status from Food and Drug Administration (FDA) in 2006 (16). This product is composed of soybean oil or cottonseed oil as sources of LCFA and palm kernel oil or coconut oil as sources of MCFA. It consists of LLL (49.5-52.7 \%), LLM or LML (37.3-39.63 \%), LMM or MLM (8.6-9.34 \%), and MMM (0.1-0.2\%) lipids. This product is also known as a healthy cooking oil which is stable at $200{ }^{\circ} \mathrm{C}$ for $30 \mathrm{~min}$. In another report, Jennings et al. (116) showed that MLM structured lipids (caprylic acid-oleic acid-caprylic acid) can be used as cooking oil for sweet potato chips at $165-185^{\circ} \mathrm{C}$ for $20-60 \mathrm{~s}$. Sensory evaluation using triangle test showed no significant difference between sweet potato chips fried using MLM structured lipids and rice bran oil (116).

MLM TAG can also be used as an ingredient for other food products such as energy bars, mayonnaise, margarine and beverages. MLM structured lipids from rice bran oil and rice bran oil were reported to be used in energy bars (116). Jacobsen et

Table 4. Conditions in a continuous reactor for medium-long-medium (MLM) type structured lipid synthesis

\begin{tabular}{|c|c|c|c|c|c|c|c|c|c|c|}
\hline Type of reaction & $\begin{array}{l}\text { Packed bed } \\
\text { reactor }\end{array}$ & Substrate & $\begin{array}{l}\text { Substrate } \\
\text { ratio }\end{array}$ & Enzyme & $\begin{array}{l}\text { Enzyme } \\
\text { loading/g }\end{array}$ & $\begin{array}{l}\text { Temp./ } \\
{ }^{\circ} \mathrm{C}\end{array}$ & $\begin{array}{l}\text { Flow rate/ } \\
\text { (mL/min) }\end{array}$ & $\begin{array}{l}\text { Residence } \\
\text { time/min }\end{array}$ & Yield & Reference \\
\hline Acidolysis & $\begin{array}{l}\mathrm{id}=0.48 \mathrm{~cm} ; \\
l=7.62 \mathrm{~cm}\end{array}$ & $\begin{array}{l}\text { Modified } \\
\text { pine nut } \\
\text { oil+capric } \\
\text { acid }\end{array}$ & $1: 5\left(n_{\mathrm{A}} / n_{\mathrm{B}}\right)$ & $\begin{array}{c}\text { Lipozyme } \\
\text { RM IM }\end{array}$ & 0.7 & 60 & 0.6 & - & $\begin{array}{l}\text { MLM lipids were } \\
\text { dominated by } \\
\text { TAG species } \\
\text { with equivalent } \\
\text { carbon number } \\
(E C N)=38\end{array}$ & (63) \\
\hline Transesterification & $\begin{array}{l}\mathrm{id}=1.15 \mathrm{~cm} ; \\
l=20 \mathrm{~cm}\end{array}$ & $\begin{array}{l}\text { Soybean oil+ } \\
\text { MCT ( } x=60 \% \\
\text { caprylic and } \\
40 \% \text { capric } \\
\text { acid) }\end{array}$ & $1: 1\left(m_{A} / m_{B}\right)$ & $\begin{array}{l}\text { Lipozyme } \\
\text { TL IM }\end{array}$ & & 55 & 0.426 & $30-40$ & $\begin{array}{c}\text { The } \\
\text { interesterfication } \\
\text { degree of } \\
\text { reaction was } \\
\text { more than } 50 \%\end{array}$ & $(42)$ \\
\hline Transesterification & $\begin{array}{l}\mathrm{id}=26 \mathrm{~mm} ; \\
l=40 \mathrm{~cm}\end{array}$ & $\begin{array}{l}\text { Fish oil+MCT } \\
(x=60 \% \\
\text { caprylic and } \\
40 \% \text { capric } \\
\text { acid) }\end{array}$ & $1: 1\left(n_{\mathrm{A}} / n_{\mathrm{B}}\right)$ & $\begin{array}{l}\text { Lipozyme } \\
\text { TL IM }\end{array}$ & & 60 & - & $30-40$ & $\begin{array}{c}\text { The } \\
\text { interesterfication } \\
\text { degree of } \\
\text { reaction was } \\
\text { more than } 80 \%\end{array}$ & (109) \\
\hline Acidolysis & $\begin{array}{l}\mathrm{id}=1.8 \mathrm{~cm} ; \\
l=18 \mathrm{~cm}\end{array}$ & $\begin{array}{l}\text { Borage } \\
\text { oil+caprylic } \\
\text { acid }\end{array}$ & $1: 2\left(n_{\mathrm{A}} / n_{\mathrm{B}}\right)$ & $\begin{array}{c}\text { Candida } \\
\text { rugosa lipase } \\
\text { (Lipase-OF) } \\
\text { and Rhizopus } \\
\text { oryzae lipase } \\
\text { (Ta-lipase) }\end{array}$ & 15 & 30 & 0.075 & - & $\begin{array}{c}\text { Produced } r=44.5 \\
\% \text { caprylic- } \gamma \\
\text { linolenic-caprylic } \\
\text { (CGC) }\end{array}$ & $(110)$ \\
\hline Acidolysis & $\begin{array}{l}\mathrm{id}=2.5 \mathrm{~cm} ; \\
l=25 \mathrm{~cm}\end{array}$ & $\begin{array}{l}\text { Tuna } \\
\text { oil+caprylic } \\
\text { acid }\end{array}$ & $1: 6\left(n_{\mathrm{A}} / n_{\mathrm{B}}\right)$ & $\begin{array}{l}\text { Lipase } \\
\text { Rd, lipase } \\
\text { Palatase }\end{array}$ & 14.1 & 30 & $0.417-1$ & - & $\begin{array}{c}\text { Produced MLM } \\
\text { lipids with } 50 \% \\
\text { of caprylic acid } \\
\text { and } 16-20 \% \text { of } \\
\text { DHA }\end{array}$ & (52) \\
\hline
\end{tabular}

$\mathrm{MCT}=$ medium chain triacylglycerol 
al. (117) reported that mayonnaise from structured lipids has a lower oxidative stability than mayonnaise from traditional sunflower oil or from chemically randomized lipids due to a lower tocopherol content, a higher initial level of lipid hydroperoxides, and a higher proportion of secondary volatile oxidation compounds. Regarding rheological properties, the type of lipid used did not affect the gel strength or the phase angle of mayonnaise (117). Osborn et al. (118) used structured lipids from canola oil and caprylic acid for the formulation of chocolate-flavoured nutritional beverages. The results showed that substituting the unmodified canola oil with structured lipids significantly improved the perception of sweetness, and decreased bubble formation. In addition, the use of MLM lipids does not change all attributes of the beverage formulation. Milk drinks from structured lipids show similar viscosity to the milk drink from sunflower oil, while lower than milk drink from randomized lipids (119). Moore and Akoh (120) used MLM product from coconut oil and sunflower oil with high oleic acid content to formulate edible film for sport nutrition products. In nutraceutical products, MLM lipids enhance the lymphatic transport and the portal absorption of the poorly water-soluble drugs and halofantrine in animal study compared to sunflower oil $(12,121)$.

\section{CONCLUSIONS}

Medium-long-medium (MLM) structured lipids have a great potential as functional ingredients in food and nutraceutical products. A careful selection of appropriate substrate, enzyme, reactor configuration and reaction conditions is necessary to increase the efficiency of MLM lipid synthesis, especially to increase yield and reduce production cost. Generally, the optimal reaction conditions for MLM lipid synthesis in batch reactor system are reaction temperature $40-60{ }^{\circ} \mathrm{C}$, enzyme load $10 \%$ ( $\mathrm{m} / \mathrm{m}$ of total substrates), stirring rate 200 $400 \mathrm{rpm}$ and reaction time 4-24 h. Immobilized lipases are widely used as catalysts for structured lipid synthesis. The reaction conditions varied depending on the reactor configuration, especially for continuous reaction. The exploration of other potential sources of substrates (lipids) and enzymes is required to increase MLM lipid yield and reduce cost. It is of importance to make the application of MLM lipids feasible for food industries.

\section{ACKNOWLEDGEMENT}

This research was funded by the Master of Education Towards Doctoral Scholarship Program for Excellence Undergraduate (PMDSU) by the Ministry of Research, Technology and Higher Education, Republic of Indonesia.

\section{ORCID IDs}

Q.D. Utama (1) https://orcid.org/0000-0002-5236-2930

A.B. Sitanggang (1) https://orcid.org/0000-0002-1378-5367

D.R. Adawiyah (1) https://orcid.org/0000-0003-0586-7183

P. Hariyadi ๑ https://orcid.org/0000-0003-2106-7725

\section{REFERENCES}

1. Karupaiah T, Sundram K. Effects of stereospecific positioning of fatty acids in triacylglycerol structures in native and randomized fats: A review of their nutritional implications. Nutr Metab. 2007;4(1):Article No. 16.

https://doi.org/10.1186/1743-7075-4-16

2. Osborn HT, Akoh CC. Structured lipids - Novel fats with medical, nutraceutical, and food applications. Compr Rev Food Sci F. 2002;1(3):110-20.

https://doi.org/10.1111/j.1541-4337.2002.tb00010.x

3. Bhandari K, Chaurasia SP, Dalai AK, Gupta A, Singh K. Kinetic study on enzymatic esterification of tuna fish oil fatty acids with butanol. J Mol Catal B Enzym. 2013;94:104-10.

https://doi.org/10.1016/j.molcatb.2013.05.006

4. Spector AA. Essentiality of fatty acids. Lipids. 1999;34(S1):S1-3. https://doi.org/10.1007/bf02562220

5. $\mathrm{Mu} \mathrm{H}$, Porsgaard T. The metabolism of structured triacylglycerols. Progr Lipid Res. 2005;44(6):430-48.

https://doi.org/10.1016/j.plipres.2005.09.002

6. Vistisen $\mathrm{B}, \mathrm{Mu} \mathrm{H}, \mathrm{H} ø y \mathrm{CE}$. Lymphatic recovery of exogenous oleic acid in rats on long chain or specific structured triacylglycerol diets. Lipids. 2006;41(9):827-34.

https://doi.org/10.1007/s11745-006-5037-2

7. Ding S, Yang JK, Yan JY. Optimization of lipase-catalyzed acidolysis of soybean oil to produce structured lipids. J Food Biochem. 2009;33(3):442-52.

https://doi.org/10.1111/j.1745-4514.2009.00227.x

8. Vandenberghe C, St-Pierre V, Pierotti T, Fortier M, Castellano CA, Cunnane SC. Tricaprylin alone increases plasma ketone response more than coconut oil or other medium-chain triglycerides: An acute crossover study in healthy adults. Curr Dev Nutr. 2017;1(4):e000257.

https://doi.org/10.3945/cdn.116.000257

9. Matulka RA, Noguchi O, Nosaka N. Safety evaluation of a medium- and long-chain triacylglycerol oil produced from medium-chain triacylglycerols and edible vegetable oil. Food Chem Toxicol. 2006;44(9):1530-8.

https://doi.org/10.1016/j.fct.2006.04.004

10. Nagao K, Yanagita T. Medium-chain fatty acids: Functional lipids for the prevention and treatment of the metabolic syndrome. Pharmacol Res. 2010;61(3):208-12.

https://doi.org/10.1016/j.phrs.2009.11.007

11. Kasai M, Nosaka N, Maki H, Negishi S, Aoyama T, Nakamura $M$, et al. Effect of dietary medium- and long-chain triacylglycerols (MLCT) on accumulation of body fat in healthy humans. Asia Pac J Clin Nutr. 2003;12(2):151-60.

12. Holm R, Porter CJH, Edwards GA, Müllertz A, Kristensen HG, Charman WN. Examination of oral absorption and lymphatic transport of halofantrine in a triple-cannulated canine model after administration in self-microemulsifying drug delivery systems (SMEDDS) containing structured 
triglycerides. Eur J Pharm Sci. 2003;20(1):91-7.

https://doi.org/10.1016/S0928-0987(03)00174-X

13. Michalski MC, Genot C, Gayet C, Lopez C, Fine F, Joffre F, et al. Multiscale structures of lipids in foods as parameters affecting fatty acid bioavailability and lipid metabolism. Progr Lipid Res. 2013;52(4):354-73.

https://doi.org/10.1016/j.plipres.2013.04.004

14. Sitompul JP, Gusdinar T, Anggadiredja K, Rahman H, Tursino. Synthesis of structured triglycerides based on canarium oil for food application. J Eng Technol Sci. 2018;50(1):87-98. https://doi.org/10.5614/j.eng.technol.sci.2018.50.1.6

15. Adamczak M, Bornscheuer UT. Application of medium engineering in the synthesis of structured triacylglycerols from evening primrose oil (Oenothera biennis L.). Eur J Lipid Sci Technol. 2013;115(4):405-12.

https://doi.org/10.1002/ejlt.201200437

16. Lee YY, Tang TK, Lai OM. Health benefits, enzymatic production, and application of medium- and long-chain triacylglycerol (MLCT) in food industries: A review. J Food Sci. 2012; 77(8):R137-44.

https://doi.org/10.1111/j.1750-3841.2012.02793.x

17. Nunes PA, Pires-Cabral P, Guillén $M$, Valero F, Luna D, Ferreira-Dias S. Production of MLM-type structured lipids catalyzed by immobilized heterologous Rhizopus oryzae lipase. J Am Oil Chem Soc. 2011;88(4):473-80. https://doi.org/10.1007/s11746-010-1702-y

18. Lee YY, Tang TK, Phuah ET, Karim NAA, Alitheen NBM, Tan $\mathrm{CP}$, et al. Structural difference of palm based medium- and long-chain triacylglycerol (MLCT) further reduces body fat accumulation in $\mathrm{DIO}$ C57BL/6J mice when consumed in low fat diet for a mid-term period. Food Res Int. 2018;103:200-7. https://doi.org/10.1016/j.foodres.2017.10.022

19. Kadhum $A A H$, Shamma MN. Edible lipids modification processes: A review. Crit Rev Food Sci Nutr. 2017;57(1):48-58. https://doi.org/10.1080/10408398.2013.848834

20. Iwasaki Y, Yamane T. Enzymatic synthesis of structured lipids. In: Recent progress of biochemical and biomedical engineering in Japan I. Advances in Biochemical Engineering, vol 90. Berlin, Germany: Springer; 2004. pp. 151-71. https://doi.org/10.1007/b94196

21. Silva RC, Cotting LN, Poltronieri TP, Balcão VM, de Almeida DB, Goncalves LAG, et al. The effects of enzymatic interesterification on the physical-chemical properties of blends of lard and soybean oil. LWT - Food Sci Technol. 2009;42(7): 1275-82. https://doi.org/10.1016/j.lwt.2009.02.015

22. Samoylova YV, Sorokina KN, Parmon VN. Prospects for application of enzymatic interesterification of oils in the production of modified fats. Catal Ind. 2016;8(4):348-53. https://doi.org/10.1134/S2070050416040097

23. Katayama M, Kuroiwa T, Suzuno K, Igusa A, Matsui T, Kanazawa A. Hydration-aggregation pretreatment for drastically improving esterification activity of commercial lipases in non-aqueous media. Enzyme Microb Technol. 2017;105:30-7. https://doi.org/10.1016/j.enzmictec.2017.06.007

24. Reis $P$, Holmberg $K$, Watzke $H$, Leser ME, Miller R. Lipases at interfaces: A review. Adv Colloid Interfac. 2009;147-148: 237-50.

https://doi.org/10.1016/j.cis.2008.06.001

25. Stergiou PY, Foukis A, Filippou M, Koukouritaki M, Parapouli $M$, Theodorou LG, et al. Advances in lipase-catalyzed esterification reactions. Biotechnol Adv. 2013;31(8):1846-59. https://doi.org/10.1016/j.biotechadv.2013.08.006

26. Hariyadi P. Enzymatic catalysis in organic solvents. J Ilmu dan Tek Pangan. 1996;1 (1):52-60 (in Indonesian).

27. Wong D. Food enzymes: Structure and mechanism. New York, NY, USA: Springer; 1995.

https://doi.org/10.1007/978-1-4757-2349-6

28. Aravindan R, Anbumathi P, Viruthagiri T. Lipase applications in food industry. Indian J Biotechnol. 2007;6:141-58.

29. Hou CT, Shimada Y. Lipases. In: Schaechter M, editor. Encyclopedia of microbiology. Amsterdam, The Netherlands: Elsevier Inc; 2009. pp. 385-92.

30. Sarmah N, Revathi D, Sheelu G, Yamuna Rani K, Sridhar S, Mehtab V, Sumana C. Recent advances on sources and industrial applications of lipases. Biotechnol Prog. 2018;34(1): 5-28.

https://doi.org/10.1002/btpr.2581

31. Adamczak M. The application of lipases in modifying the composition, structure and properties of lipids - A review. Pol J Food Nutr Sci. 2004;13/54(1):3-10.

32. Willis WM, Marangoni AG. Enzymatic interesterfication. In: Akoh CC, Min DB, editors. Food lipids: Chemistry, nutrition, and biotechnology. New York, NY, USA: Marcel Dekker, Inc; 2002. pp. 857-93.

33. Sugihara A, Shimada Y, Tominaga Y. A novel Geotrichum candidum lipase with some preference for the 2-position on a triglyceride molecule. Appl Microbiol Biotechnol. 1991; 35(6):738-40.

https://doi.org/10.1007/bf00169887

34. Kirk O, Würtz Christensen M. Lipases from Candida antarctica: Unique biocatalysts from a unique origin abstract. Org Process Res Dev. 2002;6(4):446-51.

https://doi.org/10.1021/op0200165

35. Xu X. Production of specific-structured triacylglycerols by lipase-catalyzed reactions: A review. Eur J Lipid Sci Technol. 2000;102(4):287-303.

https://doi.org/10.1002/(SICI)1438-

9312(200004)102:4<287::AID-EJLT287>3.0.CO;2-Q

36. Rodrigues RC, Fernandez-Lafuente R. Lipase from Rhizomucormiehei as a biocatalyst in fats and oils modification. J Mol Catal B Enzym. 2010;66(1-2):15-32.

https://doi.org/10.1016/j.molcatb.2010.03.008 
37. Karabulut I, Durmaz G, Hayaloglu AA. C18 unsaturated fatty acid selectivity of lipases during the acidolysis reaction between tripalmitin and oleic, linoleic, and linolenic acids. J Am Oil Chem Soc. 2010;87(11):1301-7.

https://doi.org/10.1007/s11746-010-1613-y

38. Wang Z, Du W, Dai L, Liu D. Study on lipozyme TL IM-catalyzed esterification of oleic acid and glycerol for 1,3-diolein preparation. J Mol Catal B Enzym. 2016;127:11-7. https://doi.org/10.1016/j.molcatb.2016.01.010

39. Caballero E, Soto C, Olivares A, Altamirano C. Potential use of avocado oil on structured lipids MLM-type production catalysed by commercial immobilised lipases. PLoS One. 2014;9(9):e107749.

https://doi.org/10.1371/journal.pone.0107749

40. Chnadhapuram M, Sunkireddy YR. Preparation of palm olein enriched with medium chain fatty acids by lipase acidolysis. Food Chem. 2012;132(1):216-21.

https://doi.org/10.1016/j.foodchem.2011.10.059

41. Foresti ML, Ferreira ML. Lipase-catalyzed acidolysis of tripalmitin with capric acid in organic solvent medium: Analysis of the effect of experimental conditions through factorial design and analysis of multiple responses. Enzyme Microb Tech. 2010;46(6):419-29.

https://doi.org/10.1016/j.enzmictec.2010.01.002

42. Yang H, Mu Y, Chen H, Su C, Yang T, Xiu Z. Sn-1,3-specific interesterification of soybean oil with medium-chain triacylglycerol catalyzed by lipozyme TL IM. Chin J Chem Eng. 2014;22(9):1016-20.

https://doi.org/10.1016/j.cjche.2014.06.027

43. Khodadadi M, Aziz S, St-Louis R, Kermasha S. Lipase-catalyzed synthesis and characterization of flaxseed oil-based structured lipids. J Funct Foods. 2013;5(1):424-33.

https://doi.org/10.1016/j.jff.2012.11.015

44. Casas-Godoy L, Marty A, Sandoval G, Ferreira-Dias S. Optimization of medium chain length fatty acid incorporation into olive oil catalyzed by immobilized Lip2 from Yarrowia lipolytica. Biochem Eng J. 2013;77:20-7.

https://doi.org/10.1016/j.bej.2013.05.001

45. Saw MH, Siew WL. The Effectiveness of immobilized lipase Thermomyces lanuginosa in catalyzing interesterification of palm olein in batch reaction. J Oleo Sci. 2014;63(3):295-302. https://doi.org/10.5650/jos.ess13176

46. Cao X, Mangas-Sánchez J, Feng F, Adlercreutz P. Acyl migration in enzymatic interesterification of triacylglycerols: Effects of lipases from Thermomyces lanuginosus and Rhizopus oryzae, support material, and water activity. Eur J Lipid Sci Technol. 2016;118(10):1579-87.

https://doi.org/10.1002/ejlt.201500485

47. Nunes PA, Pires-Cabral P, Ferreira-Dias S. Production of olive oil enriched with medium chain fatty acids catalysed by commercial immobilised lipases. Food Chem. 2011;127(3): 993-8.

https://doi.org/10.1016/j.foodchem.2011.01.071
48. Silroy S, Sengupta A, Bhattacharyya DK, Ghosh M. Optimization of reaction parameters of acidolysis reaction between mustard oil and capric acid by using Thermomyces lanuginosus lipase. J Food Sci Technol. 2014;51(4):715-21.

https://doi.org/10.1007/s13197-011-0543-5

49. Willett SA, Akoh CC. Application of Taguchi method in the enzymatic modification of menhaden oil to incorporate capric acid. J Am Oil Chem Soc. 2018;95(3):299-311. https://doi.org/10.1002/aocs.12043

50. Lu J, Jin Q, Wang X, Wang X. Preparation of medium and long chain triacylglycerols by lipase-catalyzed interesterification in a solvent-free system. Process Biochem. 2017; 54:89-95.

https://doi.org/10.1016/j.procbio.2016.12.015

51. Muñío MM, Robles A, Esteban L, González PA, Molina E. Synthesis of structured lipids by two enzymatic steps: Ethanolysis of fish oils and esterification of 2-monoacylglycerols. Process Biochem. 2009;44(7):723-30.

https://doi.org/10.1016/j.procbio.2009.03.002

52. Hita E, Robles A, Camacho B, González PA, Esteban L, Jiménez MJ, et al. Production of structured triacylglycerols by acidolysis catalyzed by lipases immobilized in a packed bed reactor. Biochem Eng J. 2009;46(3):257-64.

https://doi.org/10.1016/j.bej.2009.05.015

53. Costa CM, Osório NM, Canet A, Rivera I, Sandoval G, Valero F, et al. Production of MLM type structured lipids from grapeseed oil catalyzed by non-commercial lipases. Eur J Lipid Sci Technol. 2017;1700320:1-8.

https://doi.org/10.1002/ejlt.201700320

54. Ong ASH, Goh S. Palm oil: A healthful and cost effective dietary component. Food Nutr Bull. 2002;23(1):11-22. https://doi.org/10.1177/156482650202300102

55. May CY, Nesaretnam K. Research advancements in palm oil nutrition. Eur J Lipid Sci Technol. 2014;116(10):1301-15. https://doi.org/10.1002/ejlt.201400076

56. Codex standard for named vegetable oils (codex-stan 2101999). Rome, Italy: Codex Alimentarius; 1999. pp. 1-13.

57. Gunstone FD, editor. Vegetable oils in food technology: Composition, properties and uses. Oxford, UK:Wiley-Blackwell; 2011.

58. Codex standard for fish oils (codex-stan 329-2017). Rome, Italy: Codex Alimentarius; 2017. pp. 1-6.

59. Bai S, Aziz S, Khodadadi M, Bou Mitri C, St-Louis R, Kermasha S. Lipase-catalyzed synthesis of medium-long-medium type structured lipids using tricaprylin and trilinolenin as substrate models. J Am Oil Chem Soc. 2013;90(3):377-89. https://doi.org/10.1007/s11746-012-2185-9

60. Camacho Paez B, Robles Medina A, Camacho Rubio F, Esteban Cerdán L, Molina Grima E. Kinetics of lipase-catalysed interesterification of triolein and caprylic acid to produce structured lipids. J Chem Technol Biotechnol. 2003;78(4): 461-70.

https://doi.org/10.1002/jctb.810 
61. Nunes PA, Pires-Cabral P, Guillén M, Valero F, Ferreira-Dias S. Batch operational stability of immobilized heterologous Rhizopus oryzae lipase during acidolysis of virgin olive oil with medium-chain fatty acids. Biochem Eng J. 2012; 67:265-8.

https://doi.org/10.1016/j.bej.2012.06.004

62. Fomuso LB, Akoh CC. Lipase-catalyzed acidolysis of olive oil and caprylic acid in a bench-scale packed bed bioreactor. Food Res Int. 2002;35(1):15-21.

https://doi.org/10.1016/S0963-9969(00)00158-7

63. Choi JH, Kim BH, Hong SI, Kim Y, Kim IH. Synthesis of structured lipids containing pinolenic acid at the $s n-2$ position via lipase-catalyzed acidolysis. J Am Oil Chem Soc. 2012; 89(8):1449-54.

https://doi.org/10.1007/s11746-012-2040-z

64. Savaghebi D, Safari M, Rezaei K, Ashtari P, Farmani J. Structured lipids produced through lipase-catalyzed acidolysis of canola oil. J Agric Sci Technol. 2012;14(6):1297-310.

65. Wang Y, Xia L, Xu X, Xie L, Duan Z. Lipase-catalyzed acidolysis of canola oil with caprylic acid to produce medium-, long- and medium-chain-type structured lipids. Food Bioprod Process. 2012;90(4):707-12.

https://doi.org/10.1016/j.fbp.2012.02.003

66. Qin XL, Huang HH, Lan DM, Wang YH, Yang B. Typoselectivity of crude Geobacillus sp. T1 lipase fused with a cellulose-binding domain and its use in the synthesis of structured lipids. J Am Oil Chem Soc. 2014;91(1):55-62. https://doi.org/10.1007/s11746-013-2347-4

67. Liu L, Liu P, Li L, Sun JS. Production of structured lipids by enzymatic incorporation of caprylic acid into soybean oil. In: 2nd International Conference on Bioinformatics and Biomedical Engineering, 2008 May 16-18. Shanghai, PR China: IEEE; 2008. pp. 1033-7.

https://doi.org/10.1109/ICBBE.2008.253

68. Turan S, Karabulut I, Vural H. Effects of reaction parameters on the incorporation of caprylic acid into soybean oil for production of structured lipids. J Food Lipids. 2006;13(3): 306-17.

https://doi.org/10.1111/j.1745-4522.2006.00054.x

69. ÖztürkT, Ustun G, Aksoy HA. Production of medium-chain triacylglycerols from corn oil: Optimization by response surface methodology. Bioresour Technol. 2010;101(19):7456-61. https://doi.org/10.1016/j.biortech.2010.04.096

70. Yang TH, Jang Y, Han JJ, Rhee JS. Enzymatic synthesis of low-calorie structured lipids in a solvent-free system. J Am Oil Chem Soc. 2001;78(3):291-6. https://doi.org/10.1007/s11746-001-0259-2

71. Sharma S, Kanwar SS. Organic solvent tolerant lipases and applications. Sci World J. 2014;2014:Article ID: 625258

72. Kumar A, Dhar K, Kanwar SS, Arora PK. Lipase catalysis in organic solvents: Advantages and applications. Biol Proced Online. 2016;18:2.

https://doi.org/10.1186/s12575-016-0033-2
73. Zhao H, Lu Z, Bie X, Lu F, Liu Z. Lipase catalyzed acidolysis of lard with capric acid in organic solvent. J Food Eng. 2007; 78(1):41-6.

https://doi.org/10.1016/j.jfoodeng.2005.08.049

74. Elgharbawy AA, Riyadi FA, Alam MZ, Moniruzzaman M. Ionic liquids as a potential solvent for lipase-catalysed reactions: A review. J Mol Liq. 2017;251:150-66.

https://doi.org/10.1016/j.molliq.2017.12.050

75. Iwasaki Y, Yamane T. Enzymatic synthesis of structured lipids. J Mol Catal - B Enzym. 2000;10(1-3):129-40.

https://doi.org/10.1016/\$1381-1177(00)00120-X

76. Ifeduba EA, Akoh CC. Modification of stearidonic acid soybean oil by immobilized Rhizomucor miehei lipase to incorporate caprylic acid. J Am Oil Chem Soc. 2014;91(6):953-65. https://doi.org/10.1007/s11746-014-2433-2

77. Lai OM, Low CT, Akoh CC. Lipase-catalyzed acidolysis of palm olein and caprylic acid in a continuous bench-scale packed bed bioreactor. Food Chem. 2005;92(3):527-33.

https://doi.org/10.1016/j.foodchem.2004.08.028

78. Palla CA, Pacheco C, Carrín ME. Production of structured lipids by acidolysis with immobilized Rhizomucor miehei lipases: Selection of suitable reaction conditions. J Mol Catal B Enzym. 2012;76:106-15.

https://doi.org/10.1016/j.molcatb.2011.11.022

79. Pacheco C, Crapiste GH, Carrín ME. Study of acyl migration during enzymatic interesterification of liquid and fully hydrogenated soybean oil. J Mol Catal B Enzym. 2015;122: 117-24.

https://doi.org/10.1016/j.molcatb.2015.08.023

80. Zhao ML, Hu JN, Zhu XM, Li HY, Li J, Fan YW, Deng ZY. Enzymatic synthesis of medium- and long-chain triacylglycerols-enriched structured lipid from Cinnamomum camphora seed oil and camellia oil by lipozyme RM IM. Int J Food Sci Technol. 2014;49(2):453-9.

https://doi.org/10.1111/ijfs.12322

81. Khodadadi M, Kermasha S. Modeling lipase-catalyzed interesterification of flaxseed oil and tricaprylin for the synthesis of structured lipids. J Mol Catal B Enzym. 2014;102:33-40. https://doi.org/10.1016/j.molcatb.2014.01.011

82. Kawashima A, Nagao T, Watanabe Y, Kobayashi T, Ikeda I, Tominaga Y, Shimada Y. Preparation of regioisomers of structured TAG consisting of one mole of CLA and two moles of caprylic acid. J Am Oil Chem Soc. 2004;81(11):1013-20. https://doi.org/10.1007/s11746-004-1015-3

83. De Moura JMLN, Gonçalves LAG, Sarmento LAV, Cunha Petrus JC. Purification of structured lipids using $\mathrm{SCCO}_{2}$ and membrane process. J Membrane Sci. 2007;299(1-2):138-45. https://doi.org/10.1016/j.memsci.2007.04.035

84. Esteban L, Muñío MM, Robles A, Hita E, Jiménez MJ, González PA, et al. Synthesis of 2-monoacylglycerols (2-MAG) by enzymatic alcoholysis of fish oils using different reactor 
types. Biochem Eng J. 2009;44(2-3):271-9.

https://doi.org/10.1016/j.bej.2009.01.004

85. Korma SA, Zou X, Ali AH, Abed SM, Jin Q, Wang X. Preparation of structured lipids enriched with medium- and longchain triacylglycerols by enzymatic interesterification for infant formula. Food Bioprod Process. 2018;107:121-30.

https://doi.org/10.1016/j.fbp.2017.11.006

86. Arifin N, Soo-Peng K, Long K, Chin-Ping T, Yusoff MSA, Oi-Ming L. Modeling and optimization of lipozyme RM IM-catalyzed esterification of medium- and long-chain triacyglycerols (MLCT) using response surface methodology. Food Bioprocess Tech. 2012;5(1):216-25.

https://doi.org/10.1007/s11947-010-0325-5

87. Yang K, Bi Y, Sun S, Yang G, Ma S, Liu W. Optimisation of novozyme-435-catalysed esterification of fatty acid mixture for the preparation of medium- and long-chain triglycerides (MLCT) in solvent-free medium. Int J Food Sci Technol. 2014;49(4):1001-11.

https://doi.org/10.1111/ijfs.12393

88. Kawashima A, Shimada Y, Yamamoto $M$, Sugihara A, Nagao T, Komemushi S, Tominaga Y. Enzymatic synthesis of high-purity structured lipids with caprylic acid at 1, 3-positions and polyunsaturated fatty acid at 2-position. J Am Oil Chem Soc. 2001;78(6):611-6.

https://doi.org/10.1007/s11746-001-0313-0

89. Akoh CC, editor. Handbook of functional lipids. Boca Raton, FL, USA: CRC Press; 2006.

90. Rodríguez A, Esteban L, Martín L, Jiménez MJ, Hita E, Castillo $B$, et al. Synthesis of 2-monoacylglycerols and structured triacylglycerols rich in polyunsaturated fatty acids by enzyme catalyzed reactions. Enzyme Microb Technol. 2012; 51(3):148-55.

https://doi.org/10.1016/j.enzmictec.2012.05.006

91. Morales-Medina R, Muñio MM, Guadix A, Guadix EM. Development of an up-grading process to produce MLM structured lipids from sardine discards. Food Chem. 2017;228: 634-42.

https://doi.org/10.1016/j.foodchem.2017.02.019

92. Xu X. Engineering of enzymatic reactions and reactors for lipid modification and synthesis. Eur J Lipid Sci Technol. 2003;105(6):289-304.

https://doi.org/10.1002/ejlt.200390059

93. Sen P, Nath A, Bhattacharjee C. Packed-bed bioreactor and its application in dairy, food, and beverage industry. In: Larroche C, Sanroman M, Du G, Pandey A, editors. Current developments in biotechnology and bioengineering: Bioprocesses, bioreactors and controls. Cambridge, MA, USA: Elsevier; 2016. pp. 235-77.

https://doi.org/10.1016/B978-0-444-63663-8.00009-4

94. Coker AK. Industrial and laboratory reactors chemical reaction hazards and process integration of reactors. In: Coker AK, editor. Ludwig's applied process design for chemical and petrochemical plants. Oxford, UK: Gulf Professional Pub lishing; 2015. pp. 1095-208.

https://doi.org/10.1016/B978-0-08-094242-1.00021-8

95. Hamam F, Shahidi F. Enzymatic incorporation of capric acid into a single cell oil rich in docosahexaenoic acid and docosapentaenoic acid and oxidative stability of the resultant structured lipid. Food Chem. 2005;91(4):583-91.

96. Yang T, Fruekilde MB, Xu X. Suppression of acyl migration in enzymatic production of structured lipids through temperature programming. Food Chem. 2005;92(1):101-7. https://doi.org/10.1016/j.foodchem.2004.07.007

97. $\mathrm{Mu} \mathrm{H}, \mathrm{Xu} \mathrm{X,} \mathrm{Høy} \mathrm{C.} \mathrm{Production} \mathrm{of} \mathrm{specific-structured} \mathrm{tria-}$ cylglycerols by lipase-catalyzed interesterification in a laboratory-scale continuous reactor. J Am Oil Chem Soc. 1998; 75(12):1187-93.

98. Gökçe J, Şahin Yeşilcubuk N, Üstün G. Enzymatic production of low-calorie structured lipid from Echium seed oil and lauric acid: Optimisation by response surface methodology. Int J Food Sci Technol. 2013;48(7):1383-9. https://doi.org/10.1111/ijfs.12099

99. Abed SM, Wei W, Ali AH, Korma SA, Mousa AH, Hassan $\mathrm{HM}$, et al. Synthesis of structured lipids enriched with medium-chain fatty acids via solvent-free acidolysis of microbial oil catalyzed by Rhizomucor miehei lipase. LWT - Food Sci Technol. 2018;93:306-15.

https://doi.org/10.1016/j.lwt.2018.03.057

100. Lee YY, Tang TK, Phuah ET, Karim NAA, Alwi SMM, Lai OM. Palm-based medium- and long-chain triacylglycerol (P-MLCT): Production via enzymatic interesterification and optimization using response surface methodology (RSM). J Food Sci Technol. 2013;52(2):685-96. https://doi.org/10.1007/s13197-013-1065-0

101. He Y, Li J, Guo Z, Chen B. Synthesis of novel medium-long-medium type structured lipids from microalgae oil via two-step enzymatic reactions. Process Biochem. 2018; 68:108-16.

https://doi.org/10.1016/j.procbio.2018.02.005

102. Claro Da Silva R, Schaffer de Martini Soares FA, Gonzaga Fernandes T, Donadi Castells AL, Guimarães da Silva KC, Almeida Gonçalves MI, et al. Interesterification of lard and soybean oil blends catalyzed by immobilized lipase in a continuous packed bed reactor. J Am Oil Chem Soc. 2011; 88(12):1925-33.

https://doi.org/10.1007/s11746-011-1869-x

103. Paez BC, Medina AR, Rubio FC, Moreno PG, Grima EM. Production of structured triglycerides rich in $n-3$ polyunsaturated fatty acids by the acidolysis of cod liver oil and caprylic acid in a packed-bed reactor: Equilibrium and kinetics. Chem Eng Sci. 2002;57(8):1237-49. https://doi.org/10.1016/S0009-2509(02)00050-7

104. Itabaiana I, de Mariz e Miranda LS, Alves de Souza ROM. Towards a continuous flow environment for lipase-catalyzed 
reactions. J Mol Catal B Enzym. 2013;85-86:1-9.

https://doi.org/10.1016/j.molcatb.2012.08.008

105. H-Kittikun A, Kaewthong W, Cheirsilp B. Continuous production of monoacylglycerols from palm olein in packed-bed reactor with immobilized lipase PS. Biochem Eng J. 2008;40(1):116-20.

https://doi.org/10.1016/j.bej.2007.11.023

106. No DS, Zhao T, Kim BH, Choi HD, Kim IH. Enrichment of erucic acid from crambe oil in a recirculated packed bed reactor via lipase-catalyzed ethanolysis. J Mol Catal B Enzym. 2013;87:6-10.

https://doi.org/10.1016/j.molcatb.2012.10.001

107. Camacho F, Robles A, Camacho B, González PA, Esteban $L$, Molina E. Modeling of the kinetic for the acidolysis of different triacylglycerols and caprylic acid catalyzed by lipozyme IM immobilized in packed bed reactor. Chem Eng Sci. 2007;62(12):3127-41.

https://doi.org/10.1016/j.ces.2007.03.011

108. Gonzáles Moreno PA, Robles Medina A, Camacho Rubio F, Páez B, Molina Grima E. Production of structured lipids by acidolysis of an EPA-enriched fish oil and caprylic acid in a packed bed reactor: Analysis of three different operation modes. Biotechnol Progr. 2004;20(4):1044-52.

https://doi.org/10.1021/bp034314c

109. Xu X, Porsgaard T, Zhang H, Adler-Nissen J, Høy C-E. Production of structured lipids in a packed-bed reactor with Thermomyces lanuginosa lipase. J Am Oil Chem Soc. 2002; 79(6):561-5.

https://doi.org/10.1007/s11746-002-0522-6

110. Kawashima A, Shimada Y, Nagao T, Ohara A, Matsuhisa T, Sugihara A, Tominaga Y. Production of structured TAG rich in 1,3-dicapryloyl-2- $\gamma$-linolenoyl glycerol from borage oil. J Am Oil Chem Soc. 2002;79(9):871-7.

111. Nagata J, Kasai M, Watanabe S, Ikeda I, Saito M. Effects of highly purified structured lipids containing medium-chain fatty acids and linoleic acid on lipid profiles in rats. Biosci Biotechnol Biochem. 2003;67(9):1937-43.

https://doi.org/10.1271/bbb.67.1937

112. Ikeda I, Tomari Y, Sugano M, Watanabe S, Nagata J. Lymphatic absorption of structured glycerolipids containing medium-chain fatty acids and linoleic acid, and their effect on cholesterol absorption in rats. 1991;26(5):369-73. https://doi.org/10.1007/BF02537201
113. Wijesundera C, Ceccato C, Watkins P, Fagan P, Fraser B, Thienthong N, Perlmutter P. Docosahexaenoic acid is more stable to oxidation when located at the $s n-2$ position of triacylglycerol compared to $s n-1$ (3). J Am Oil Chem Soc. 2008;85(6):543-8.

https://doi.org/10.1007/s11746-008-1224-z

114. Tengku-Rozaina TM, Birch EJ. Positional distribution of fatty acids on hoki and tuna oil triglycerides by pancreatic lipase and 13C NMR analysis. Eur J Lipid Sci Technol. 2014; 116(3):272-81.

https://doi.org/10.1002/ejlt.201300357

115. Carvajal O, Sakono M, Sonoki H, Nakayama M, Kishi T, Sato $M$, et al. Structured triacylglycerol containing medium-chain fatty acids in sn-1(3) facilitates the absorption of dietary long-chain fatty acids in rats. Biosci Biotechnol Biochem. 2000;64(4):793-8.

https://doi.org/10.1271/bbb.64.793

116. Jennings BH, Shewfelt RL, Akoh CC. Food applications of a rice bran oil structured lipid in fried sweet potato chips and an energy bar. J Food Qual. 2010;33(6):679-92.

https://doi.org/10.1111/j.1745-4557.2010.00355.x

117. Jacobsen C, Xu X, Skall Nielsen N, Timm-Heinrich M. Oxidative stability of mayonnaise containing structured lipids produced from sunflower oil and caprylic acid. Eur Food Res Technol. 2003;105(8):449-58.

https://doi.org/10.1002/ejlt.200300796

118. Osborn HT, Shewfelt R, Akoh CC. Sensory evaluation of a nutritional beverage containing canola oil/caprylic acid structured lipid. J Am Oil Chem Soc. 2003;80(4):357-60. https://doi.org/10.1007/s11746-003-0703-3

119. Timm-Heinrich M, Xu X, Skall Nielsen N, Jacobsen C. Oxidative stability of milk drinks containing structured lipids produced from sunflower oil and caprylic acid. Eur J Lipid Sci Technol. 2003;105(8):459-70. https://doi.org/10.1002/ejlt.200300795

120. Moore MA, Akoh CC. Enzymatic Interesterification of coconut and high oleic sunflower oils for edible film application. J Am Oil Chem Soc. 2017;94(4):567-76. https://doi.org/10.1007/s11746-017-2969-z

121. Holm R, Porter CJH, Müllertz A, Kristensen HG, Charman WN. Structured triglyceride vehicles for oral delivery of halofantrine: Examination of intestinal lymphatic transport and bioavailability in conscious rats. Pharm Res. 2002; 19(9):1354-61.

https://doi.org/10.1023/A:1020311127328 